\title{
Fragmentos da babadeirai história drag brasileira
}

\section{Fragments of the controversial Brazilian drag history}

\section{Fragmentos de la controvertida historia drag brasileña}

\author{
Lucas Bragança \\ lucasbragancafonseca@gmail.com | https://orcid.org/0000-0001-9627-5049 \\ ${ }^{1}$ Universidade Federal Fluminense. Niterói, RJ, Brasil. \\ a Mestrado em Comunicação e Territorialidades pela Universidade Federal do Espírito Santo.
}

\section{Resumo}

Protagonistas nas lutas LGBTs, as drag queens viveram constantemente um apagamento histórico, fruto do preconceito estrutural que envolve, inclusive, a própria comunidade LGBT. No entanto, contemporaneamente, a cultura drag vive um momento de forte presença midiática suscitada pela popularização do programa estadunidense RuPaul's Drag Race. Tendo isso em vista, o presente artigo visa elaborar um entendimento sobre o percurso histórico que possibilitou a construção da cultura drag, tal qual a compreendemos contemporaneamente. Além disso, busca situar esses sujeitos como importantes na história LGBT mundial, observando sua presença, também, na cultura e mídia brasileiras.

Palavras-chave: Mídia; Drag; Cultura; LGBT; Transformismo.

\begin{abstract}
Protagonists in the LGBT struggles, drag queens have constantly lived a historical erasure, as a result of the structural prejudice that involves, even, the own LGBT community. However, at the same time, the drag culture lives a moment of strong media presence raised by the popularization of the American program RuPaul's Drag Race. Taking this into account, this article aims to elaborate an understanding of the historical path that allowed the construction of the drag culture as we understand it contemporaneously. In addition, it seeks to situate these subjects as important in LGBT world history, noting their presence, also, in Brazilian culture and media.
\end{abstract}

Keywords: Media; Drag; Culture; LGBT; Transformism.

\footnotetext{
i No pajubá, léxico LGBT brasileiro, o termo "babado" possui caráter polissêmico. Um "babado" pode tanto significar algo extremamente positivo, quanto negativo ou mesmo ser sinônimo de "fofoca" e "polêmica", a depender do contexto. Além disso, o termo também funciona como um advérbio de intensidade.
} 


\section{Resumen}

Protagonistas de las luchas LGBT, las drag queens experimentan un borrado histórico, como consecuencia del prejuicio estructural que implica, incluso, la propia comunidad LGBT. Sin embargo, al mismo tiempo, la cultura del arrastre vive un momento de fuerte presencia de los medios levantada por la popularización del programa norteamericano RuPaul's Drag Race. Teniendo esto en cuenta, este artículo tiene como objetivo elaborar una comprensión del recorrido histórico que permitió la construcción de la cultura drag como la entendemos contemporáneamente. Además, busca situar esos temas como importantes en la historia mundial LGBT, observando su presencia, también, en la cultura y los medios brasileños.

Palabras clave: Medios; Drag; Cultura; LGBT; Transformismo.

Este texto faz parte do dossiê $\mathbf{4 0}$ anos do movimento LGBT: visibilidades e representações.

Contribuição dos autores: o autor é responsável por todo o texto.

Declaração de conflito de interesses: não há conflitos de interesses.

Fontes de financiamento: artigo desenvolvido sob o financiamento da Coordenação de Aperfeiçoamento de Pessoal de Nível Superior (Capes) durante mestrado em Comunicação e Territorialidades, na Universidade Federal do Espírito Santo. O artigo também recebeu contribuição do edital de Diversidade Cultural, em 2017, da Secretaria de Estado da Cultura do Espírito Santo, para construção do livro 'Desaquendando a História Drag: no Mundo, no Brasil e no Espírito Santo'.

Considerações éticas: não há.

Agradecimentos/Contribuições adicionais: agradeço à Erly Vieira Jr. pelo apoio e orientação em toda empreitada do desenvolvimento desta pesquisa durante do mestrado.

Histórico do artigo: submetido: 08 fev. 2019 | aceito: 10 jul. 2019 | publicado: 12 set. 2019.

Apresentação anterior: não há.

Licença CC BY-NC atribuição não comercial. Com essa licença é permitido acessar, baixar (download), copiar, imprimir, compartilhar, reutilizar e distribuir os artigos, desde que para uso não comercial e com a citação da fonte, conferindo os devidos créditos de autoria e menção à Reciis. Nesses casos, nenhuma permissão é necessária por parte dos autores ou dos editores. 


\section{Introdução}

É notório o fato de que, na contemporaneidade, as drag queens estão em franca ascensão cultural. Isso pode ser facilmente percebido, por exemplo, na cena musical brasileira por meio do sucesso de cantoras drag como Aretuza Lovi, Gloria Groove e, principalmente, Pabllo Vittar. Roger Baker ${ }^{1}$ percebeu em sua investigação acerca da genealogia das drag queens, que a presença desses indivíduos é uma constante na história humana. O que buscamos aqui, então, é a construção de uma historicidade midiática desenvolvida à luz do método genealógico foucaultiano que, levando em conta as formações discursivas de um objeto, busca compreender seu processo de naturalização. Dessa maneira, o estudo pode colaborar com a elucidação do momento contemporâneo de expansão da cultura drag nos espaços midiáticos e seu reflexo em outros espaços sociais.

O reavivamento cultural drag não representa algo necessariamente novo, já que houve algumas explosões culturais drag na história ocidental. Assim, mesmo com inserções pontuais durante as décadas anteriores e de certa notoriedade em parte da década de 1990 através, por exemplo, de grandes sucessos cinematográficos como Priscilla, Rainha do Deserto (dirigido por Stephan Elliott em 1994) e Gaiola das Loucas (dirigido por Mike Nichols em 1996), do show de transformistas no programa do Silvio Santos, ou mesmo contratações frequentes de shows de transformismo em eventos sociais, foi apenas no fim dos anos 2000, mais precisamente em 2009, com o lançamento do programa RuPaul's Drag Race ${ }^{\text {ii }}$ que as drags atingiram um outro escopo, mais amplo².

Se antes as drag queens estavam em uma posição de figura de entretenimento exótico, apresentada isolada e esporadicamente, garantindo o cumprimento da 'cota de diversidade', atualmente, elas se reapresentam midiaticamente de forma mais ampla e articulada, explicitando suas regras internas, sua comunidade e sua rearticulação lúdica da ambiguidade de gênero - características que, por sua vez, passam a ressoar num tipo de plateia que também passa a querer ser drag. Assim, percebe-se uma nova virada tanto na presença midiática desses indivíduos quanto de sua percepção por parte da sociedade.

Se para alguns pensadores, Tdisc "o século se anuncia como um tempo de mudança nos discursos e nas práticas da sexualidade"3, no Brasil contemporâneo é possível observar um crescimento de políticas de caráter conservador, especialmente acerca das dissidências de sexualidade e gênero. Os exemplos são abundantes: a escandalização relativa à arte e sexualidade 4 , a polêmica envolvendo a visita da drag Femmenino à uma escola infantiliii, os cercamentos da população LGBT ${ }^{\text {iv }}$ no Rio de Janeiro por meio de uma política religiosa ${ }^{5}$ e a legitimação desse pensamento via eleição de um presidente permeado de polêmicas que envolvem os mais variados preconceitos. Isso tudo sem esquecermos, claro, de sermos o lugar onde mais se mata homossexuais do mundo.

O fato é que essas ações vêm ocorrendo simultaneamente ao momento em que uma das cantoras de maior sucesso é uma drag queen. Surge, portanto, um ambiente social repleto de contradições em que a discussão sobre temas voltados à comunidade LGBT se torna extremamente pertinente, especialmente os casos que conseguem contrariar o levante de conservadorismo.

O papel protagonista das drag queens ${ }^{\vee}$ nas rebeliões de Stonewall - marco das lutas pela liberação das sexualidades dissidentes no mundo ocidental - já as coloca como indivíduos de extrema relevância histórica

ii Trata-se de um reality show de competição entre drag queens para eleger anualmente 'a próxima drag superstar'. O programa é exibido no canal VH1 nos Estados Unidos e, no Brasil, disponibilizado pela Netflix.

iii Junto à Universidade Federal de Viçosa, a artista gravou um vídeo intitulado: 'Na hora do lanche' em uma escola infantil no Dia das Crianças. Nele, Femmenino fala "não existir coisas de menino e menina", e, nesse momento, uma criança espontaneamente fala "isso é preconceito!". Apenas essa interação foi o suficiente para que se levantasse uma onda de reações na Internet. Não apenas a Universidade e o artista mantiveram suas posições, como o fato acabou gerando também um levante de manifestações de apoio, como da Secretaria Estadual de Direitos Humanos e da Ordem dos Advogados do Brasil (OAB).

iv Utilizaremos durante todo o estudo a sigla LGBT - ao invés, por exemplo, de LGBTTTIQA+ (lésbicas, gays, bissexuais, travestis, transexuais, transgêneros, intersexuais, queer, assexuais e outras possibilidades) por ser, ainda, a sigla mais em uso pelos movimentos sociais, como o GGB - Grupo Gay da Bahia https://grupogaydabahia.com.br/. Entendemos, no entanto, que a sigla não contempla toda a gama da sexualidade humana.

v Vale ressaltar que o termo drag queen no contexto estadunidense da época funcionava como um termo guarda-chuva para diversas manifestações de expressão de gênero que envolvessem a exibição de uma 'figura feminina'. 
que hoje se encontram potencializados por um alcance midiático. Se, conforme Lauretis ${ }^{6}$, os discursos, dos quais a mídia é contemporaneamente um dos maiores produtores, contribuem para reificar as restrições estereotipadas impostas para diferenciar o masculino do feminino, as drag queens, em um contrafluxo, possuem o potencial denunciativo que desregula o establishment.

No Brasil, a cantora Glória Groove (alter ego de Daniel Garcia Felicione Napoleão), homem gay, negro e gordo, é um claro exemplo. Glória é cantora de rap, um território ocupado majoritariamente por homens prioritariamente heterossexuais. Em um terreno onde ser gay ou ser mulher representa uma ruptura ao ideal do rap, um homem gay travestido com elementos femininos, cantando no feminino letras que abordam questões relativas ao gênero e à sexualidade, coloca alguns obstáculos na compreensão imediatista que temos quando vemos alguma performance artística.

Para a realização da análise, foram seguidas algumas das concepções do método arqueológico proposto por Foucault ${ }^{7}$, tendo em vista sua busca em detectar a formação histórica do discurso de um objeto dentro do meio social, observando como se formou e se legitimou uma visão específica. Além disso, para o desenvolvimento da dissertação e do livro, dos quais este artigo se origina, foi realizado um levantamento histórico científico e documental, bem como cerca de vinte entrevistas semiestruturadas com drag queens e transformistas ${ }^{\text {vi }}$ que tenham performado por algum período desde a década de 1980 até o presente momento. Essas entrevistas foram pensadas como forma de não construir apenas um revisionismo histórico, mas de propagar, também, as experiências e específicas dessas vivências.

As performances de gênero fazem parte dos mais diversos contextos artísticos e midiáticos. Estão presentes, por exemplo, em programas de fofoca ${ }^{\text {vii }}$, são personagens sempre presentes nas comédias ${ }^{\text {viii, }}$ programas de televisão $0^{\text {ix }}$ e, mais ainda, no teatro ${ }^{x}$. Porque, então, falamos hoje sobre um reavivamento cultural drag? O fato é que esse tipo de performance drag está, muitas vezes, tão enraizada socialmente que não abala o statu quo. É possível ver, por exemplo, pessoas extremamente preconceituosas gargalhando com personagens femininos nas comédias de Paulo Gustavo. A problemática surge quando, na equação perceptiva do público, a dimensão da sexualidade aparece, já que, desde os tempos do teatro Elisabetano os atores sempre tiveram permissão de violar códigos tanto estéticos quanto religiosos ${ }^{1}$.

Enquanto se entende o transformismo e a performance drag somente a partir da perspectiva de um homem que atende (ao menos em parte) às expectativas de gênero masculinas 'fingindo ser' uma mulher, também atendendo às expectativas do que seria uma mulher, especialmente quando existir um caráter cômico, essa performance não gera maiores discussões. No entanto, quando essas dimensões ficam turvas a partir de uma performance que mistura as categorias de gênero, identidade e sexualidade, elas se tornam uma questão às vistas da sociedade.

Assim, não nos interessa, neste estudo, o conceito amplo de drag queen, mas, precisamente, as drag queens que 'brincam' também com as dimensões de gênero e que fogem das dicotomias homem-mulher e masculino-feminino não apenas em suas performances, mas, muitas vezes, em seus próprios estilos de vida.

vi Ainda que haja especificidades entre os dois movimentos, tanto drag queens quanto transformistas tratam da modificação estética, em geral feminina, do corpo. No entanto, as transformistas se prolongaram até meados da década de 1990 e funcionava como um termo que abarcava homens gays que se montavam, travestis e outras possibilidades. 0 termo drag, mesmo que também tenha tido essa funcionalidade nos EUA, chega ao Brasil em um momento de distinção e ressignificação entre essas categorias e passa a denotar apenas homens que se montavam².

vii Por exemplo: Mamma Bruschetta, personagem de Luiz Henrique participante do programa Fofocalizando da Rede TV e Tia, personagem de Guilherme Uzeda no programa Mulheres da TV Gazeta.

viii Pensemos na personagem Carol Paixão de Rodrigo Sant'anna e sua atuação em programas de humor na Globo e no Multishow. Além disso, poderíamos citar Vera Verão (alter ego de Jorge Lafond), personagem de imensa popularidade nas décadas de 1980 e 1980 e da Velha Surda (personagem de Roni Rios) do programa A Praça é Nossa.

ix Erick Barreto, por exemplo, era um notório personificador feminino que se apresentava em shows de calouros brasileiros. Da mesma forma, Isabelita dos Patins, personagem de Jorge Omar Iglesias, era figura constante nos programas de auditório nacionais.

$x$ Lembremos, por exemplo, das Divinas Divas do Teatro Rival do Rio de Janeiro, de Silvetty Montilla na comédia Terça Insana ou mesmo das diversas personagens presentes nas peças teatrais de Paulo Gustavo. 


\section{As manas de outros tempos}

Resgatar uma historicidade midiática da cultura drag no entretenimento não é uma tarefa simples. Além de poucas bibliografias que tratem especificamente sobre o conceito de drag, muitas delas não se encontram acessíveis em acervos brasileiros, traduzidas para o português ou mesmo disponíveis em plataformas digitais - mesmo ilegais - de compartilhamento de arquivos. Roger Baker ${ }^{1}$ foi um dos pioneiros na tentativa de sistematizar um pensamento sobre esses indivíduos buscando a sintetização de conhecimento histórico, não apenas sobre as personificadoras femininas (que seriam, de acordo com o autor, próprias da teatralidade), como se empenhou em abranger também, em edições posteriores, as drag queens mais contemporâneas e pertencentes à cultura LGBT.

Em sua pesquisa, o autor ${ }^{1}$ notou que a mimetização do corpo em figuras do gênero oposto ocorre desde o início da história humana, mesmo em culturas e épocas distintas e geograficamente distantes umas das outras. Para Baker ${ }^{1}$, são essas variadas construções do corpo ao longo da história que propiciaram o desenvolvimento da figura drag queen, tal qual a entendemos hoje e, por isso, fazem parte de sua historicidade.

Os primeiros registros encontrados pelo autor datam de antes do período clássico grego e mostram que papéis de representação feminina eram desempenhados por homens em festivais folclóricos que marcavam as mudanças de estação e em outros rituais. No entanto, é a partir da civilização grega que se encontram mais facilmente registros documentais da presença da performance de gênero.

Como aponta Amanajás ${ }^{8}$, o próprio surgimento das máscaras teatrais se dá por conta da necessidade do homem em mimetizar-se ou transformar sua aparência. Desde esse período era papel dos homens a interpretação de personagens femininos; fato que será uma constante na história, variando apenas qual tipo de poder (estatal, social ou religioso) realizará os ditames e convenções sociais. Os homens não apenas faziam uso das máscaras na interpretação de personagens femininos, bem como "roupas e enchimentos também eram adicionados para a composição da personagem"s.

Na Idade Média europeia, quando a igreja era o principal formador e regulador social, a performance de gênero ficava restrita às representações sacras de partes da Bíblia. Os homens eram os encarregados por todos os papéis, incluindo os femininos, visto que era vetada a participação de mulheres em grande parte da vida social' ${ }^{1}$. Do outro lado do mundo, o caráter de dominância masculina também existia. Por meio de uma forma de teatro ritualística e formal, nos diversos estilos teatrais asiáticos, desde os clássicos chineses e japoneses (Kyogen e Nô), ao Topeng e Wayang Wong da Indonésia e ao Kathakali da Índia, eram também os homens os representantes de todos os papéis.

De volta ao ocidente, por volta do século XVI, começaram a surgir as companhias de teatro itinerantes italianas completamente desassociadas da igreja e geralmente voltadas à comédia. Concomitantemente, na Inglaterra, surgia o teatro Elisabetano, em que "os papéis femininos escritos por Shakespeare ${ }^{x i}$ ou qualquer outro dramaturgo eram interpretados por jovens adolescentes homens - meninos entre dez e treze anos". Como aponta Silvério Trevisan ${ }^{9}$, desde os autos catequéticos dos jesuítas, ocorridos por volta desse mesmo período histórico, os raros papéis femininos eram todos interpretados por homens, "como a personagem de uma velha em Na festa de São Lourenço, do padre José de Anchieta, representada pelos índios ainda no século XVI”.

Segundo Baker ${ }^{1}$, em 1674 houve uma mudança basilar na cultura teatral: as mulheres conquistaram o direito de subirem aos palcos e interpretarem papéis femininos. A presença da mulher no teatro "se tornou um mecanismo de exploração da sexualidade feminina, fazendo com que suas habilidades cênicas fossem as últimas das preocupações da plateia”. Essas atrizes acumulavam, muitas vezes, funções de cortesãs.

xi É recorrente a visão de que Shakespeare, ao escrever suas peças, utilizava a sigla DRAG (dressed as a girl - vestido como mulher) para indicar os personagens femininos que seriam protagonizados por homens. No entanto, se a própria existência de Shakespeare como o real autor das peças (e não, por exemplo, um pseudônimo) é até hoje questionada, essas afirmações são realizadas sem base concreta. Aliás, se pensarmos que nesse período da história do teatro praticamente todos os personagens eram realizados por homens, o sentido da indicação de um homem vestido como mulher no roteiro seria absolutamente irrelevante. 
"No final do século XVII, o ator feminino havia se tornado uma figura cômica, uma criatura do burlesco e da paródia. Suas aparições no palco durante os próximos 150 anos ou mais eram ocasionais, mas pelos meados do reinado Vitoriano sua reabilitação estava em andamento" .

Por aqui, a realidade não era muito distante. Mesmo que houvesse proibição das mulheres subirem aos palcos desde 1780, por meio de uma lei promulgada pela rainha Maria I, suas participações eram comuns ${ }^{\mathrm{xii}}$. Com o tempo, as personificações femininas vivenciaram um declínio. Tais performances se tornaram raras no âmbito teatral, visto que homens se travestindo com elementos femininos haviam se tornado motivo de piada.

Foi apenas no século XVIII que apareceram indivíduos que mesclavam essas performances com a homossexualidade. Nesse ensejo, na Inglaterra surgem as Molly Houses, complexos ambientes de socialização homossexual que tentavam abarcar todas as possibilidades sexuais e de gênero negadas e perseguidas socialmente, visto que a sodomia era considerada crime. Aqui era comum o cross-dressing ${ }^{\mathrm{xiii}}$, o simulacro de casamentos, a prostituição e a realização de fetiches ${ }^{9}$.

Nesse mesmo período, na Itália, dentro da arte da ópera, ganharam força as figuras do castrati; meninos, geralmente italianos órfãos ou de famílias desfavorecidas, que eram vendidos à igreja para que se juntassem aos coros. Os castrati, muitas vezes, também desempenhavam nesses espetáculos os papéis femininos. Para tanto, suas genitálias eram mutiladas ainda crianças (daí o nome castrati que em português significa castrado) para que suas vozes não se modificassem com a chegada da adolescência ${ }^{8}$. Vários castratis italianos que viviam em Portugal foram trazidos para o Brasil em 1808 junto com a comitiva do rei D. João VI em sua fuga de Napoleão Bonaparte, onde passaram a cantar na Capela Real9 .

Já no século XIX, homens frequentavam ambientes conhecidos como Music Hall, espaços onde brilhavam as 'pantonímicas', um tipo de performance de canto e de realização de pequenos papéis cômicos que também envolviam a personificação feminina. No Rio de Janeiro, esses espaços existiam no entorno do Largo do Rossio (atual Praça Tiradentes), o qual, já muito antes de 1870, era identificado como um espaço de circulação homoerótica ${ }^{10}$. Assim, a personificação feminina “[...] entrou no século XX com largo sorriso, as mãos na cintura, vestindo roupas estranhas parodiado a alta moda, um ninho de pássaro como peruca e uma maquiagem descontroladamente exagerada. [...] seu humor era robusto e terrenamente doméstico quando ele ganhou a confiança do público e compartilhou as provações da vida conjugal. Ele se tornou a dama pantomímica; amplamente popular, habitada por todos os principais comediantes da época”.

Com a I Guerra Mundial (1914-1918), houve profundas mudanças sociais que repensaram os papéis de gênero dentro da sociedade, colocando o homem como um herói de guerra, exemplo de virilidade, e as mulheres como ativas, trabalhadoras e mais independentes. Nesse período começa a crescer um movimento anti-homossexual que se proliferou em toda a mídia impressa e colocou as personificações femininas no anonimato por mais de uma década ${ }^{1}$.

O grande desenvolvimento tecnológico da II Guerra Mundial (1939-1945) ocasionou a melhora nos aparelhos televisivos que prontamente se alastraram pelas residências mundo afora e foram transformados na predominante fonte de entretenimento, fazendo com que os teatros de variedade e comédia stand up fossem sendo deixados de lado pelo público ${ }^{8}$. Com isso, as possibilidades da personificação feminina cômica foram cerceando, ao mesmo tempo em que a televisão, o cinema, a cultura pop e os movimentos sociais de raça, gênero e sexuais foram surgindo, desenvolvendo novas possibilidades ao longo das décadas subsequentes.

xii No capítulo "Reminiscências da cena travestida" de seu livro9 ${ }^{9}$ Trevisan faz um brilhante trabalho, a partir de documentos históricos, de arqueologia dessas performances teatrais por todo o território nacional.

xiii Termo que trata sobre o ato de uma pessoa utilizar roupas e objetos socialmente associados ao sexo oposto. 


\section{A ferveção da cena transformista}

No ano de 1969, ocorreram em Nova York as rebeliões de Stonewall, consideradas um dos marcos das lutas LGBTs para a sociedade ocidental. Durante toda a revolta, o papel das drag queens (como de transexuais, transgêneros e travestis) ${ }^{\text {xiv }}$ foi não apenas determinante, mas protagonista, sendo parte da liderança do acontecimento atribuída a Sylvia Rivera e Marsha P. Johnson ${ }^{\mathrm{xv}}$. Como a própria Sylvia fala: "[...] as pessoas trans de rua e as drag queens foram a vanguarda do movimento [...] nós ficamos na frente e lutamos contra a polícia. Fomos nós que não nos importamos de levar paulada na cabeça”"1.

As revoltas em Stonewall forneceram o combustível para a ampliação das lutas políticas dos grupos ativistas nos Estados Unidos e em grande parte do mundo ${ }^{x v i}$. Essa expansão, como consequência, estimulava mais pessoas a saírem do armárioxvii. "Os homossexuais, de maneira organizada, passaram a se mobilizar pelo direito de expressar sua afetividade e sexualidade sem serem hostilizados ou terem de se submeter a uma vida dupla. Inspiraram-se não só no movimento feminista, mas na luta pelos direitos civis dos negros e nos protestos contra a guerra, que os havia sensibilizado a não tolerar injustiças sociais" ${ }^{\prime 2}$.

Esses movimentos sociais estadunidenses ocorriam quase "paralelamente às contestações contra a ditadura em 1967 e 1968: os protestos contra a censura, as críticas crescentes sobre a falta de liberdades democráticas e um sentimento

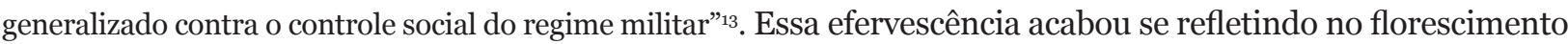
de cenas culturais essencialmente gays ou, ao menos, sexualmente expandidas nas grandes cidades.

Exemplo disso é o teatro de revista brasileiro. "Oriundo da França, mas devidamente digerido e transformado no Brasil, esse gênero teatral abrasileirou-se, passando em revista os acontecimentos, ideias e costumes da época, tudo de forma cômica. Através das revistas musicais, lançavam-se canções de carnaval e novas beldades, que se tornavam padrões de beleza nacional. O público acorria para ver nos palcos as mais belas vedetes, que se exibiam em roupas sumárias, dançando em meio a cenários luxuosos que incluíam fontes luminosas - tudo ao som de grandes orquestras"9. Com o tempo, o luxo e a qualidade na indústria do entretenimento caíram, e o cômico passou a ser mais próximo ao obsceno, dando lugar ao teatro do rebolado e - já em concorrência com a programação televisiva - ao show das travestis, ou shows de transformismo ${ }^{\text {xiii, }}$. Assim, se a personificação feminina no mundo esteve geralmente atrelada à história do teatro, no Brasil não foi diferente.

Não há como precisar o início do transformismo no Brasil, mas apontamentos de Trevisan ${ }^{9}$ dizem que em 1921 o jornal Estado de S.Paulo já noticiava que no palco do Cine São Paulo havia um imitador do belo sexo, mostrando que essa cena é ainda mais antiga. Da mesma forma, as performances de gênero já eram parte consolidada dentro do universo carnavalesco, e Madame Satã já apresentava sua Mulata do Balacochê na vida noturna e marginal da Lapa, no Rio de Janeiro.

Além disso, o fenômeno do travestismo dentro do teatro brasileiro não era algo restrito apenas aos grandes centros urbanos. Como fala Trevisan: "em Porto Alegre, por volta de 1830, existiu uma certa 'sociedade de teatrinho' que mantinha em seu elenco alguns rapazes especializados em papéis femininos”7. Da mesma forma: "no estado do Maranhão, conhecem-se programas de representações teatrais de meados do século XIX, nos quais os homens

xiv Qualquer determinação sobre os universos drag queen, travesti, transexual e transgênero, nessa época, é limitado, visto que esse período histórico repressivo fazia com que muitos jovens trans vivessem uma vida dupla, performando gênero em momentos específicos como drag queens.

xv A própria tentativa de enquadramento de Marsha P. Johnson em uma das categorias (drag, trans e travesti) é frustrada, como visto em no documentário11: "Ele não liga a mínima se veste de roupas de homem ou de mulher. É totalmente livre. Se ele quiser se vestir como homem, se veste. Ou como mulher, se veste de mulher. Se quiser usar patins, usa. Tanto faz". Marsha responde olhando para a câmera: "Isso mesmo".

xvi Vale ressaltar que é também nessa conjuntura que aparece com mais força a medicalização da sexualidade, em que a psiquiatria e a psicologia estimulavam a 'cura gay' por meio de métodos de aversão, choques elétricos ou mesmo da lobotomia.

xvii Expressão parte do léxico gay, o Pajubá. Usada para designar um homem ou mulher que assumiu sua sexualidade não normativa perante sua família e comunidade.

xviii É preciso pontuar que o termo 'transformista', nesse período, funcionava como o termo 'drag queen' nos Estados Unidos, ou seja, como uma nomenclatura que abarcava sexualidades, gêneros e expressões distintas sob um único termo. 
faziam todos os papéis femininos - como um certo Augusto Lucci, que interpretava o personagem Dorotéia, filha de um juiz, na ópera-cômica A vendedora de perus, apresentada em 1985”.

Fato é que, por muito tempo, os ditos 'ambientes gays' eram os centros sociais da vida homossexual. Os homossexuais, cientes da rejeição social, convergiam (e ainda convergem) sua sociabilidade para ambientes próprios: bares, boates, cafés, clubes, tudo para criar espaços de liberdade distantes dos olhares de desaprovação da sociedade. Assim, as apresentações de transformismo não ficavam apenas centralizadas nos teatros, mas se expandiram rapidamente para as casas noturnas.

No começo da cena drag de São Paulo, as drags/transformistas cantavam ao vivo acompanhadas de um conjunto. A popularização das dublagens só viria a acontecer posteriormente. Essa cena acabou se desenvolvendo muito rápido, ao menos em São Paulo, como aponta o depoimento da Miss Biá14: "Comecei a receber convites pra trabalhar em tudo que era canto. Cheguei a fazer 5 casas por noite. Novidade todo mundo quer ver, né? Pessoal da sociedade ia, o pessoal hétero, não era casa gay, não existia casa gay. Isso em 6o, até um pouco antes".

Sérgio Mendes conta que “os anos 70 foi uma década bicha. Joel Gray fazia Cabaret, um ícone da época, você tinha Secos e Molhados, Dzi Croquettes ${ }^{\mathrm{xix}}$, David Bowie [...] Era a androginia, o amor livre”"14. Nesse período começam a aparecer casas noturnas que misturavam o público gay e hétero, mas que tinham como grandes estrelas os shows das transformistas. Como fala Edy Star, uma dessas estrelas andróginas setentistas brasileiras: "Nos anos 70, o que eu me lembro muito bem dentro da classe gay são os espetáculos do teatro, da riqueza, do glamour. 20 e tantas, 30 travestis em cena, todos muito bem vestidos, com um grande balé"14.

O nascimento dessa cultura foi tão veloz que, quando se faz uma pesquisa no acervo digital da Folha de S.Paulo utilizando o termo 'transformismo', a década de 1960 aparece com apenas 2 resultados, enquanto a década de 1970 já possui 181 citações sobre essas performances.

No Rio, nesse período, a região da Cinelândia era o centro cultural da cidade. Lá, em diversos teatros, as transformistas brilhavam em espetáculos produzidos com capricho e sofisticação. Dentre eles, o teatro Rival, onde Rogéria, Valéria, Jane Di Castro, Camille K, Fujika de Holliday, Eloína dos Leopardos, Marquesa e Brigitte de Búzios formaram um grupo conhecido como Divinas Divas, hoje, eternizado pelo documentário de mesmo nome, dirigido por Leandra Leal em 2016.

Uma das primeiras casas noturnas de São Paulo foi a K-7, um pequeno sobrado na Bela Cintra que tinha como donos Elisa Mascaro e Fernando Simões, dois empresários que viriam a ser os grandes patronos da cena gay paulistana. As batidas policiais eram constantes, e os problemas com a vizinhança fizeram os donos abrirem outra boate em agosto de 1971, o Medieval - casa que viria a se tornar referência histórica não apenas na cena transformista ${ }^{\mathrm{xx}}$ e drag nacional, mas também na comunidade LGBT. Personalidades nacionais como Eva Vilma, Chiquinho Scarpa, Fafá de Belém, Vanderléia e Hebe eram figuras constantes nos eventos do Medieval, mostrando que o lugar, apesar de se apresentar como gay, era frequentado pelas mais variadas sexualidades, mas não necessariamente por todos os estratos sociais.

O ápice dos eventos no Medieval acontecia na festa anual Broadway, e os frequentadores colocavam toda sua criatividade em cena. Segundo Kaka di Polly ${ }^{14}$, as coisas que aconteciam nesse evento eram tão inimagináveis que parecem mentira. Para ilustrar, ele conta dois casos icônicos dos eventos do Medieval: "Você imagina um Darby Daniel chegando carregado por 7 anões num caixão de vidro, vestido de branca de neve? Aí me vem um cara num cavalo branco, descia do cavalo, tirava a tampa de vidro e dava um beijo na boca do Darby. Aí o

xix Dzi Croquettes foi um grupo teatral e de dança brasileiro atuante entre 1972 e 1976. As peças continham monólogos, números de dança e canto, mas o grande destaque era o visual dos atores, sempre carregados de maquiagem e do uso de trajes femininos. Essa inadequação de gênero chamou a atenção da ditadura que censurou o espetáculo. A trupe foi então para a França, onde alcançou sucesso com o apoio de Liza Minelli, colaborando com o cineasta Claude Lelouch no filme Le Chat et la Souris (1975).

xx Indico o trabalho de Bortolozzi (2015) "A arte transformista brasileira: rotas para uma genealogia decolonial" para maiores explicações sobre as aproximações entre as travestis, os artistas transformistas e as drag queens nesse período. 
Darby cuspia uma maçã e entrava dentro da boate. Você imagina uma cena dessa acontecendo? É assim que elas faziam pra chegar. Você imagina a Wilza Carla, em cima de um elefante subindo a rua Augusta. Ela vestida de odalisca?”14.

Os shows do Medieval eram como Paris, regados a muita pluma e muito paetê. No entanto, enquanto lá os shows eram realizados por mulheres, por aqui ficava a cargo das transformistas ${ }^{14}$. O sucesso da casa fez com que a cena gay se tornasse pungente em boa parte das grandes capitais brasileiras e diversificasse seus públicos. Em São Paulo, por exemplo, diversas iniciativas tiveram início nesse período: a boate Nostro Mondo (que funcionou até 2014) e a boate Homo Sapien, mais conhecida como HS, que tinha como frequentadores personalidades internacionais como Freddie Mercury. Segundo Leão Lobo: "o HS começou a dar uma coisa mais moderna, mais americana porque além das travestis, tinham as comédias (realizadas por Meise Emanuel e Veneza)”14.

Alternativas não pareciam faltar, especialmente na rua Marquês de Itu, em São Paulo, onde casais homossexuais já circulavam livremente de mãos dadas. A casa Val Improviso era uma dessas. Lá frequentavam, como conta Erika Palomino para a Folha de S.Paulo, "bandidos, mocinhas, drags, semidrags, clubbers, DJs, travas e boys; descolados, famosos, herdeiros milionários e artistas”.15. Isso, é claro, além de prostitutas, travestis de rua, garçons e outras pessoas que ganhavam a vida no turno noturno. O lugar ficou imortalizado nos versos da música Só as mães são felizes, de Cazuza: "Você nunca varou / A Duvivier às 5 / Nem levou um susto / Saindo do Val Improviso".

A profissionalização das drag queens e travestis na época era sem precedentes. Na Corintho, haviam 16 performers e 12 bailarinos, além dos outros 67 funcionários. Todas que trabalhavam lá tinham carteira assinada, décimo terceiro, férias pagas, INSS ${ }^{14}$. Os shows eram montados e ficavam em cartaz de 6 a 7 meses, às vezes por até um ano.

Essa valorização artística, no entanto, não se traduzia em aceitação social. Como conta Miss Biá, uma das mais importantes transformistas paulistanas, elas não podiam sair de peruca na cabeça, "a gente tinha que carregar na mão pra não ser presa. Tinha delegado que, se visse, se pegasse no meio da rua, levava presa e ficava um, dois dias presas"14.

Episódios como esse eram comuns pelo fato de os homossexuais viverem à mercê da Lei da Vadiagem. Essa lei se aplicava a todos que não estivessem dentro da normatividade esperada e que não estivessem com documentação em mãos e carteira de trabalho assinada. Trejeitos 'femininos', utilização de roupas 'do sexo oposto' e utilização de maquiagens por 'homem' eram motivos suficientes para se prender alguém ${ }^{13}$. No entanto, a lei era ainda mais precisa com travestis, transexuais e transformistas, já que suas próprias existências davam à polícia o poder de encarceramento.

Enquanto isso, nos anos 1980, das seis peças de teatro de revista que estavam em cartaz no Rio de Janeiro, quatro eram protagonizadas por transformistas ${ }^{7, x x i}$. Como consequência dessa notoriedade, algumas transformistas conquistaram reconhecimento. Rogéria ganharia o Troféu Mambembe, concedido pelo Instituto Nacional de Artes Cênicas, como revelação de atriz por seu trabalho em O Desembestado, de Ariovaldo Matos; Andréa de Mayo interpretou uma travesti em A Ópera do Malandro, de Chico Buarque; Claudia Wonder atuou na versão teatral de Nossa Senhora das Flores, de Jean Genet, bem como em O Homem e o Cavalo, de Oswald de Andrade9.

Essa abertura do cenário musical e teatral brasileiro acabou sendo um dos maiores propulsores para a entrada das transformistas na televisão. O programa Show de Calouros, no ar a partir de 1977 no SBT, criou uma categoria específica para essa performance. O concurso das transformistas ${ }^{\mathrm{xxii}}$ virou, então, um dos maiores destaques do programa. Nomes como o de Erick Barreto, transformista que interpretava uma personagem chamada Diana Finks fazendo imitações de várias artistas do mundo da música, se tornaram célebres. No caso de Erick, sua personificação de Carmen Miranda, tão realística, chegou a lhe render o

xxi Um exemplo é a peça escatológica protagonizada por Laura de Vison, uma drag queen que se inspirava no personagem Divine (uma drag queen americana progatonista de filmes de Gavin Waters) para realizar suas performances.

xxii Várias dessas performances encontram-se disponíveis no Arquivo Transformistas em: http://bit.ly/2Dj9anL. 
protagonismo no filme Carmen Miranda: Bananas is my Business (1995) de Helena Solberg por indicação da própria irmã de Carmen Miranda.

Em suas performances em plena TV aberta brasileira, Eric, muitas vezes, realizava apresentações que se iniciavam com sua figura dentro dos padrões de um homem heterossexual, sofrendo uma transformação em pleno palco, tendo como ápice a exibição de uma figura feminina. Ao som de Y’a Du Soleil Sur Paris de Line Renaud, por exemplo, Eric aparecia no palco vestindo um smoking e, durante sua interpretação, ia aplicando maquiagem, se despindo de suas roupas 'masculinas' até se transformar em uma exuberante mulher.

Erick, inclusive, se colocava como um bancário transformista e utilizava as pequenas aberturas midiáticas para colocar as pautas das transformistas, como ao final de uma performance no Programa da Hebe, no SBT, em que ele fala: "É muito lindo, de repente, você abrir esse canal pra gente. Porque a gente trabalha há tanto tempo, há tantos anos [...] é muito difícil a gente quebrar esse estigma, essa barreira, sabe? Que proíbe o transformista, pessoas fantásticas, de ocupar um espaço desses a nível nacional” ${ }^{\prime 1}$.

A cena transformista talvez tenha sido, até então, o momento mais articulado e abrangente das performances de gênero no contexto brasileiro. Suas apresentações extrapolaram as simples apresentações em ambientes LGBTs para pessoas LGBTs, conquistando notoriedade midiática e valorização artística.

\section{Os babados fortes do desenvolvimento do drag}

A liberação homossexual propulsionada pelos movimentos da década de 1960 não veio acompanhada, proporcionalmente, por aceitação social. Assim, era enorme o número de homens e mulheres gays que eram renegados por suas famílias e amigos e ficavam desamparados. Nesse contexto, no começo dos anos 1980, uma subcultura nova-iorquina essencialmente negra e gay, a ball culture, ganha maiores proporções, redefinindo noções de família, masculinidade e amizade.

Eternizada no documentário Paris is Burning ${ }^{17}$, de Jennie Livingston, a ball culture, ou cultura dos bailes, eram eventos realizados por grupos que se intitulavam houses (casas), onde existia uma cadeia hierárquica de homens e mulheres homossexuais formulada a partir de seus desempenhos nos bailes. Essas casas promoviam um ambiente para além da liberdade sexual, mas um local de refúgio. Os bailes, feitos por e para homossexuais periféricos, tinham como objetivo a apresentação individual em desfiles e a disputa por troféus em diversas categorias.

A origem desses bailes é atrelada aos bailes drags do Harlem dos anos 1920 e 1930. Eles aconteciam, em grande parte, às três ou quatro da madrugada, para que os participantes pudessem andar pela cidade montados e de salto alto em maior segurança. Esse horário também permitia que o aluguel dos salões para os bailes fosse mais barato, bem como garantia a participação da classe trabalhadora noturna - garotos de programa, travestis e transexuais que ganhavam suas vidas com a prostituição, bem como de garçons e outros trabalhos que perduravam durante a madrugada ${ }^{18}$.

Foi apenas no final dos anos 1970 e começo dos 1980 que se iniciou o fenômeno das houses, ambientes que se tornavam redes alternativas de parentesco, por intermédio da figura de uma mother (mãe) e, às vezes, de um father (pai) que tinham suas childrens (crianças), compostas por pessoas que não tinham nenhum parentesco sanguíneo. O documentário de Livingston ${ }^{17}$ mostra que, para muitas dessas pessoas, as relações familiares das houses eram tanto quanto ou mais profundas e afetivas que as relações familiares sanguíneas. "A criação de casas transformou o circuito drag para sempre quando novas populações, algumas das quais nunca se sentiram atraídas a bailes de drag, entraram na comunidade. Uma taxonomia rica de pessoas e identidades de gênero floresceu: prostitutos que eram 'novos' para a cultura gay, as lésbicas de mocassim com vínculos eróticos com homens gays, estilistas negros e fashionistas ansiosos para colocar suas roupas 'para teste' na nova cena urbana. $\mathrm{O}$ termo 'drag' agora significava algo muito mais rico que apenas homens vestidos como mulheres" ${ }^{\text {”8 }}$. 
Nesse momento, drag passou a ser uma metáfora da vida cotidiana, todos, de uma forma ou outra, estariam performando uma identidade específica, independente do cross-dressing estar evolvido. Foi nesse ambiente que surge o vogue ${ }^{x x i i}$, um estilo de dança que, pelo próprio nome, se espelha na moda, em especial, nas poses das modelos presentes nas revistas. O vogue é uma dança abertamente afeminada composta por movimentos corporais definidos.

A cultura dos bailes influenciou profundamente o conceito de $d r a g$, não apenas a partir da visão expansiva de que a performance drag não estaria atrelada à representação do gênero oposto, mas uma exploração do próprio corpo, da mimetização, do simulacro, mas também da linguagem, da dança e do sistema de redes de apoio ${ }^{\text {xxiv }}$.

Concomitante à parte da cena da ball culture, mas do outro lado da cidade e em outro estrato social, cultural e racial, se desenvolvia a cena dos club kids, um movimento que tinha como figura central Michael Alig. Alig começou a promover festas de grande sucesso em grandes casas noturnas nova-iorquinas repletas de celebridades e pessoas da 'alta sociedade'. Ele também realizava festas 'fora da lei', em lugares públicos ou mesmo particulares, como em estações de metrô, restaurantes, casas abandonadas, entre outros.

O ápice desses eventos ocorria, justamente, com a chegada da polícia ${ }^{19}$. Juntamente a seus amigos ${ }^{\mathrm{xxv}}$, Alig criava alter egos, personas e personagens: drag queens, góticos, andróginos, bizarros, irreverentes ou qualquer outra possibilidade que a criatividade permitisse. Eles viriam, mais tarde, a serem conhecidos como club kids.

Esse grupo usava roupas ultrajantes, sendo definido por James St. James ${ }^{19}$ como "parte drag, parte palhaço, parte infantilismo". Essa estética abraçava o capitalismo americano, ao mesmo tempo que zombava dele. Faziam graça das convenções sociais e criavam um espaço de sociabilidade para indivíduos que se sentissem desajustados socialmente. Mesmo que tenha existido por um curto tempo, a cultura club kid, sua estética, seu humor satírico e irônico são também características importantes para grande parte da cena drag contemporânea.

Em meados dos anos 1980 outro fator ganha importância no entendimento de toda história LGBT: a epidemia da AIDS. O HIV e a AIDS significavam, na época, duas coisas: a morte social, dado o preconceito com a doença; e a morte física. Para Susan Sontag ${ }^{20}$, a experiência da epidemia da AIDS reavivou a relação pré-moderna entre doença e morte, já que nesse período as enfermidades eram "misteriosas, e a passagem de uma doença grave para a morte era algo normal". Esse, inclusive, foi o principal motivo para a cultura dos bailes entrar em colapso, já que o falecimento de várias mães e pais acabou desestruturando a organização das casas.

Os movimentos sociais das sexualidades, crescentes desde Stonewall por todo mundo ocidental, tiveram, a partir da crise da AIDS, que repensar suas bandeiras e reivindicar não apenas respeito, mas sua própria sobrevivência. Desde o começo da epidemia, a imprensa já havia batizado a nova enfermidade como "câncer gay” ${ }^{\prime 2}$, ao mesmo tempo que o meio científico adotaria a sigla DIRG (doença imunológica relacionada aos gays), embora essa visão seja infundada, frente ao alcance epidêmico que abrangeu todos gêneros, sexualidades, raças e faixas etárias.

A escolha da terminologia ao tratar da doença acabou por ser determinante em sua associação direta com os homossexuais e seu comportamento sexual, culminando em duas realidades opostas: uma nova volta ao armário dos homossexuais e uma saída do armário forçada daqueles que tinham o vírus.

No auge da epidemia, como conta Chica Chiclete, drag capixaba: "as famílias desovavam seus parentes na porta dos hospitais e os abandonavam como animais”. A epidemia da AIDS e o caos que ela instaurou nas comunidades LGBTs, portanto, foram determinantes nas décadas seguintes não apenas por terem

xxiii Posteriormente o vogue chegou ao mainstream através da música de mesmo nome de Madonna, no álbum l'm Breathless: Music from and Inspired by the Film Dick Tracy de 1990, em que a cantora utilizou não apenas elementos da cena da ball culture, como também os próprios dançarinos dos bailes do Harlem.

xxiv No Brasil, por exemplo, há anualmente o BH Vogue Fever, um encontro internacional de dançarinos e entusiasta do vogue realizado em Belo Horizonte. O evento conta com workshops e aulas com convidados internacionais, ball com batalhas de vogue etc. Mais informações em: http://bit.ly/2DaLhyz.

xxv Alguns club kids viriam a se tornar notórios na cena drag, como RuPaul e Amanda Lepore. 
modificado as pautas das lutas sociais, mas também porque reavivou um sentimento anti-gay fomentado pela visão pejorativa e estereotipada que fundia o vírus com a homossexualidade.

O preconceito, o medo e os estigmas potencializados pela associação da AIDS com a homossexualidade gerou reações violentas da sociedade, sendo mais incisivo ainda em travestis e transexuais ${ }^{\mathrm{xxv}}$ que, acoplados a essa questão, já sofriam violência por suas especificidades de gênero. Prova disso são as capas de jornal mostradas no documentário Temporada de Caça ${ }^{21}$ : "Delegado compara atentados contra travestis com a moda de atirar bolinhas de gude nas vitrines das lojas" e "Comando anti-gay faz a sétima vítima".

A normalização da violência era comum. No próprio documentário ${ }^{21}$ uma repórter faz a seguinte pergunta a transeuntes: "Você acha que deveriam matar travestis?" e o entrevistado prontamente responde: "Eu acho que se a lei permite isso, seria uma boa, né?”. Além disso, carros circulavam por São Paulo exibindo o adesivo com os dizeres: "Mate um Paulo Ricardo hoje e evite um Ney Matogrosso amanhã". Como coloca Perlongher ${ }^{21}$ : "Infelizmente, a caça às bichas ou a caça aos viados foram uma espécie de esporte lamentavelmente bastante populares em alguns países como países latino-americanos e também no Brasil. E o lamentável é que esse tipo de esporte é considerado como uma espécie de acontecimento natural".

Como maneira de se afastar da imagem estereotipada do gay afeminado de 'comportamento promíscuo', grande parte da comunidade LGBT passou a viver cada vez mais de acordo com os padrões heterossexistas de sociedade. As características masculinas passaram a ser cada vez mais enaltecidas, enquanto as femininas, rechaçadas. A AIDS, então, acabou tendo forte impacto na cena transformista. A partir desse momento não era mais cool frequentar ambientes com homossexuais. Os shows, assim, perderam seu público, e a cena foi se desestruturando.

É nesse mesmo período que a cena midiática estadunidense causa grandes impactos na cena performática: as músicas de RuPaul passam a habitar as rádios em 1993; Priscila, a Rainha do Deserto, com direção de Stephan Elliott, é lançado em 1994 nos cinemas do circuito independente; e, logo depois, em 1995, no circuito de cinemas de shopping mais mainstream, é lançado Para Wong Foo, Obrigada por Tudo! Julie Newmar, com direção de Beeban Kidron - eventos determinantes na publicização de um novo padrão estético. É a partir desse período que a cultura drag, tal qual a compreendemos hoje, passa a existir no Brasil.

Trevisan conta que a partir da década de 1990: "A atuação das drag queens foi facilitada por englobar um componente lúdico e satírico semelhante ao das caricatas do carnaval, o que as levou a transitar por áreas jamais imaginadas, como as concorridas festas de socialites, shows beneficentes e colunas sociais da grande imprensa" Exemplo disso são as drags repórteres. Nomes como Nany People e Léo Áquila se tornam comuns na mídia e são exemplos de drag queens que galgaram novos espaços.

Essa profunda repaginação da estética e da cultura drag ocorreu não apenas por influência das tendências internacionais vindas com produtos midiáticos, mas também visando a busca por sobrevivência por meio de uma reformulação cultural que estivesse mais alinhada às novas demandas das casas noturnas. Isso porque, quase simultaneamente, houve uma mudança do paradigma musical em que a música eletrônica passa a reger as casas noturnas e o $D J$ passa a ser a figura central da noite.

Nesse ensejo, as drogas sintéticas também se popularizam, sendo mais um motivador para que a música eletrônica substituísse as dublagens das artistas transformistas na noite, tendo em vista a mudança de postura dos próprios frequentadores das casas noturnas, mais interessados na batida e na exploração dos sentidos que no interrompimento da noite proporcionados pelas performances ${ }^{2}$.

É nesse momento que surge o bate-cabelo, um estilo de dança criado por Márcia Pantera e disseminado por todo país. Nele, as drags, embaladas no ritmo frenético das músicas eletrônicas, giram o cabelo em uma velocidade impressionante objetivando levar o público ao delírio. Essa onda mercadológica global que repaginou as drag queens como ícones pop, menos sexualizadas que as travestis e transformistas e mais lúdicas, ocorreu 
também como uma resposta à crise da AIDS, colocando a performance drag como de um homem que apenas performava, diferentemente da visão mesclada de gênero e sexualidade que existia nas transformistas.

A visão politizada das drag queens desde os enfrentamentos de Stonewall também se tornou parte das características da cultura drag no Brasil, sendo as drag queens extremamente participativas, por exemplo, nas Paradas do Orgulho LGBT. Exemplo disso é que na primeira Parada LGBT que viria a acontecer em 1997 em São Paulo (mesmo que já houvesse algumas movimentações anteriores), o papel das drag queens foi muito além de estarem na linha de frente, mas de participarem da própria organização por intermédio de nomes como Kaká Di Polly e Salete Campari. Kaká Di Polly conta que: "Chegou na última hora, não queriam deixar a Parada sair. Eu cheguei para o Roberto de Jesus e falei: 'Olha Beto, eles não querem deixar o carro sair, eu vou fazer um negócio ali na frente e quando eu fizer, você aproveita para colocar o carro na rua e fazer a passeata sair"'. Eu fui lá na frente, fingi que estava passando mal, me joguei no chão e o trânsito da Paulista parou. No que o Roberto de Jesus viu o trânsito da Paulista parado, ele fez o carro entrar na avenida e todo mundo foi atrás. Tinha só umas duas mil pessoas. Aí me levantei e saí correndo atrás da Parada e os guardas ficaram todos com cara de idiotas"14.

Por muitos anos, de acordo com Kaká, o principal papel das drags nas Paradas era de levar visibilidade, já que seus corpos decorados e espalhafatosos funcionavam como "verdadeiros carros alegóricos", "uma flor no meio de uma procissão" ${ }^{14}$. As transformistas levavam público para as paradas, já que seu reconhecimento artístico fazia com que fossem consideradas algo próximo de celebridades para parte da comunidade LGBT. Além disso, esses corpos espetaculares atiçavam a curiosidade da própria população que, mesmo lateralmente, participava da Parada como público.

Ao longo das duas décadas seguintes, a presença das drag queens na grade televisiva foi se reduzindo, mas não cessou xxvii. Programas como Show de Variedades e, posteriormente, o Novo Show de Calouros, ambos no SBT, nunca deixaram de exibir as performances das drag queens e transformistas. No entanto, o ápice da cena drag foi fugaz, e essa cultura caiu em certo ostracismo por volta dos anos 2000.

\section{Arrasando na contemporaneidade}

Mesmo com papel proeminente nos enfrentamentos da revolta de Stonewall e também na linha de frente das primeiras manifestações LGBT públicas no Brasil, as drag queens e as travestis não eram (e não são) apenas oprimidas no sistema das instituições sociais 'tradicionais', mas também, muitas vezes, vistas com desdém dentro da comunidade LGBT. É interessante perceber que mesmo dentro de uma cultura e um movimento em que se busca a liberdade individual, alguns corpos são vistos como mais legítimos que outros, especialmente os corpos que lidam com as questões de gênero de uma forma não normativa, reafirmando noções heterossexualizadas que oprimem a comunidade em diferentes níveis.

Pouco explorada epistemologicamente, a cultura drag possui uma rica história. Essa composição de fragmentos aqui apontados buscou mostrar que a personificação feminina sempre esteve presente na história humana e que estiveram e continuam como importantes articulares nos momentos de tensionamento político com a sociedade. Grande parte das transformistas e drag queens soube e sabe estimular risadas e articular política com a mesma destreza.

No Brasil, a cultura transformista encontrou um espaço de produção artística dentro do teatro e das casas noturnas que produziam grandes espetáculos utilizando essas performers como pilares da noite. No entanto, após a crise da AIDS instaurada no final da década de 1980, a comunidade LGBT, que vinha conquistando espaço sociale galgando inclusão como reflexo de uma valorização artística das transformistas e dos movimentos sociais, voltou a ser mais hostilizada.

xxvii Foi realizada uma pesquisa pela plataforma do YouTube na qual encontramos diversos vídeos dos anos 1990 e 2000. Disponível em: http://bit.ly/2rfNGmj. 
Como maneira de se afastar da imagem estereotipada do gay afeminado de 'comportamento promíscuo', grande parte da comunidade LGBT passou a viver cada vez mais de acordo com os padrões heterossexistas de sociedade. Isso contribuiu para que as performances de gênero passassem a ser malvistas inclusive dentro da própria comunidade LGBT.

Por meio de produtos midiáticos estadunidenses, a cultura drag - que se diferenciava da cultura transformista por, em geral, não buscar a composição de uma figura feminina realista - chega ao Brasil e é adaptada para o contexto nacional. Mesmo com as tentativas de adequação, por meio de uma nova visualidade e composição artística que se articulava com o novo panorama musical, ao longo das décadas, o show de drag nas boates foi deixando de ser um momento esperado até se tornar algo indesejável.

É apenas em 2009, novamente no contexto estadunidense, que a cultura drag ganha um novo estímulo: o programa RuPaul's Drag Race. O reality, que já caminha para a $12^{\text {a }}$ temporada (sem contar os spin-offs), rapidamente se tornou uma coqueluche na comunidade LGBT. Ele foi o combustível que reascendeu o interesse da indústria do entretenimento pela cultura drag e, especialmente em uma juventude LGBT.

Esse novo momento criou uma aura celebratória da cultura drag, além de recriarem a visão das drag queens como celebridades. Com isso, proliferam-se programas e figuras midiáticas drag. Podemos citar, para além das conhecidas cantoras drag, programas de televisão como o Drag me as a Queen do canal E!, apresentado pelas drag queens Penelopy Jean, Rita von Hunty e Ikaro Kadoshi; a websérie Academia de Drags, apresentada por Silvetty Montilla; o sucesso de Lorelay Fox e seu canal no YouTube; e a primeira animação protagonizada por drag queens, Super Drags, disponibilizada pela Netflix, entre outros.

Isso deixa perceptível que a performance drag no território midiático nacional vive, já há algum tempo, uma dualidade que se dá pela sua habitação tanto dos espaços das casas noturnas quanto de sua articulação como figuras midiáticas. Essas corporeidades exuberantes se colocam como perfeitas figuras do entretenimento, atendendo a demandas da mídia. Assim, mesmo que a cultura drag esteja se articulando midiaticamente de forma mais ampla, essa relação não representa necessariamente um fato novo.

Hoje, o Brasil compõe uma das maiores comunidades de fãs do programa no mundo e, mesmo com esse novo êxtase sobre a cultura $d r a g$, as entrevistadas apontaram que essas mudanças não parecem ser estruturais. O novo público consumidor drag parece mais interessado nessa nova estética proposta pelo programa e cooptada pelas novas drags brasileiras que se envolver estruturalmente com a cultural. Assim, um grupo de artistas se encontra ainda em uma realidade bem menos glamourizada. Além disso, a ampliação do conceito de drag que vem abrangendo mulheres cis drag queens (tendo em conta que as mulheres trans já habitam esse universo), drag kings e outras possibilidades ainda parece não encontrar grandes espaços tanto na grade televisiva quanto na cena noturna.

Como forma de adaptação, as jovens drag queens relataram que hoje suas performances vão além de uma performance de gênero composta pela dança e dublagem, mas também se aliam ao trabalho de DJs, recolocando a si mesmas como figuras centrais da noite a partir das demandas da cena contemporânea. Os novos contornos da cena contemporânea vêm conjuntamente levantando inúmeras questões como as aqui apontadas e que necessitam de aprofundamento e pesquisa para serem respondidas.

Como fala Miss Linda², uma drag veterana capixaba: "Nós passamos muitas coisas, nós fomos presas, fomos rejeitadas, fomos ignoradas e vencemos. Atravessamos décadas!”. Daí: “a necessidade de agrupar essas informações para essa geração nova, elas precisam saber que nós sofremos da nossa maneira para hoje elas poderem bater seu cabelo [...] elas têm que olhar para trás e respeitar. Fomos nós quem proporcionamos o caminho para toda essa efervescência, esse modismo, esse filão que é a comunidade LGBT".

Esta é a principal conclusão do estudo. A cultura drag não nasce ou simplesmente ressurge com as novas representações midiáticas, como RuPaul's Drag Race, mas é fruto, tanto quanto, de uma luta política e de uma disputa e conquista por espaço midiático iniciadas há décadas no território nacional. 


\section{Referências}

1. Baker R. Drag: a history of female impersonation in the performing arts. New York: New York University Press; 1994.

2. Bragança L. Desaquendando a história drag: no mundo, no Brasil e no Espírito Santo. Vitória: Edição Independente; 2018.

3. Preciado PB. Manifesto contrassexual. São Paulo: n-1 edições; 2017.

4. Herdy T. Manifestações contrárias à exposição Queermuseu foram 17 vezes mais vistas nas redes. 0 Globo (Grupo Globo) [Internet]. 2017 set. 27 [citado em 2019 jul. 16]. Disponível em: https://glo. bo/2EUO6kJ.

5. Segunda maior parada LGBT do país pode não acontecer por causa de Crivella. Esquerda Diário (editor desconhecido) [Internet]. 2017 out. 10 [citado em 2019 jul. 16]. Disponível em: http://bit.ly/2E7yhpz.

6. Lauretis T. A tecnologia do gênero. In: Hollanda H. Tendências e impasses: o feminismo como crítica da cultura. Funck S, tradutora. Rio de Janeiro: Rocco; 1994. p. 206-242.

7. Foucault M. História da sexualidade 1: a vontade de saber. Rio de Janeiro: Paz \& Terra; 2017.

8. Amanajás I. Drag queen: um percurso histórico pela arte dos atores transformistas. Rev Belas Artes [Internet]. 2014 set.-dez.:16. Disponível em: http://bit.ly/2xSbKyb.

9. Trevisan JS. Devassos no paraíso: homossexualidade Brasil. Rio de Janeiro: Record; 2000.

10. Figari C. @s outr@sCariocas: interpelações, experiências e identidades homoeróticas no Rio de Janeiro: séculos XVII ao XX. Belo Horizonte: Editora UFMG; Rio de Janeiro: IUPERJ; 2007.

11. France D. A morte e a vida de Marsha P. Johnson [documentary]. France D, Teodosio LA, Reed K, producers. California: Netflix; 2017. 1h 45min.

12. Timerman A, Magalhães N. Histórias da AIDS. São Paulo: Autêntica; 2015.

13. Green JN, Quinalha R, organizadores. Ditadura e homossexualidades: repressão, resistência e a busca pela verdade. São Carlos: EdUFSCar; 2014.

14. Steffen L. São Paulo em Hi-Fi [documentário]. Lima E, Steffen L, produtores. [São Paulo]: [O autor]; 2015. 101min.

15. Palomino E. Histórias de um underground brasileiro [Internet]. Folha de S. Paulo (Grupo Folha). 2000 maio (acesso em 2019 jul. 12): Ilustrada. Disponível em: https://bit.ly/2I7QKcE.

16. Tranformista Erik Barreto na Hebe Camargo [Internet]. São Paulo. SBT; 2010. 5min 19s.

17. Livinston J. Paris is burning [documentary]. California: Netflix; 1990. 1h 16min.

18. Roberts FL. There's no place like home: a history of house ball culture. WireTap Mag [Internet]. 2007 June [cited 2019 July 15]. Available from: https://bit.ly/2GdZ6vQ.

19. Bailey F, Barato R. Party Monster. [Local desconhecido]: [editor desconhecido]; 2003. 93 min.

20. Sontag S. AIDS e suas metáforas. São Paulo: Companhia das Letras; 1989.

21. Moreira R. Temporada de caça [documentário]; [Local desconhecido]: [editor desconhecido]; 1988. $28 \mathrm{~min} 36 \mathrm{~s}$. 